\title{
132. Preliminary Accounts on the Chromosomal Polymorphism in the Field Mouse, Apodemus giliacus, a New Form from Hokkaido*)
}

\author{
By Isamu Hayata, **) Hachiro Shimba,**) Tsuneaki \\ KoBAYAShI, $* * *)$ and Sajiro MAKINo**)
}

(Comm. by Yoshimaro TanakA, M. J. A., June 12, 1970)

Based on morphological and oecological studies, Kobayashi (1970) described Apodemus giliacus as a new form of the genus Apodemus occurring in Hokkaido. This species is characterized by a medium-sized body, and its external characters and size of skull are evident being intermediate between $A$. speciosus and $A$. argenteus. These three species are clearly distinguishable by the shape of nasal bone from each other (see Kobayashi, 1970). Interesting is the chromosomal polymorphism occurring in this new form of Apodemus. Preliminary data derived from ten specimens are reported in the following.

Materials and methods. Ten specimens of Apodemus giliacus were collected from Sapporo, Naganuma, Shibecha, and Oketo in Hokkaido in a period from July to October, 1969. The animals were captured alive and their chromosomes were investigated with short term cultures of bone marrow cells by means of the routine air-drying method. The marrow cells from the femur were colchicinized for 1.5 hours, treated with hypotonic $\mathrm{KCl}$ solution for 20 minutes at $37^{\circ} \mathrm{C}$, fixed in methanol-acetic acid $(3: 1)$, air-dried on slides and stained with Giemsa.

Findings and remarks. Chromosome counts from ten specimens are presented in Table I. The diploid numbers of chromosomes established in each from the modal value were surprising by showing a wide variation: 48 for specimen no. 9, 49 for no. 7, 50 for no. 8, 52 for nos. 4, 5 and 6, 53 for no. 1, 54 for no. 3, 55 for no. 10 and 59 for no. 2. There were considerable variations of the chromosome number within the same individual; they were mostly noted as hypo-modal values. It is most probable that they were derived from broken cells.

*) Contributions from the Chromosome Research Unit, Faculty of Science, Hokkaido University, Sapporo.

**) Chromosome Research Unit, Faculty of Science, Hokkaido University, Sapporo.

***) Institute of Applied Zoology, Faculty of Agriculture, Hokkaido University, Sapporo. 
Table I. Distribution of chromosome numbers in bone marrow cells of ten specimens of Apodemus giliacus studied

\begin{tabular}{|c|c|c|c|c|c|c|c|c|c|c|c|c|c|c|c|c|}
\hline \multirow{2}{*}{$\begin{array}{c}\text { Specimen } \\
\text { no. }\end{array}$} & \multicolumn{14}{|c|}{ Chromosome number distribution } & \multirow{2}{*}{$\begin{array}{c}\text { Total cells } \\
\text { counted }\end{array}$} & \multirow{2}{*}{$2 \mathrm{n}$} \\
\hline & 46 & 47 & 48 & 49 & 50 & 51 & 52 & 53 & 54 & 55 & 56 & 57 & 58 & 59 & & \\
\hline 1 & & & & & & 1 & 6 & 43 & & & & & & & 50 & 53 \\
\hline 2 & & & & & & & & & & & 2 & 3 & 10 & 35 & 50 & 59 \\
\hline 3 & & & & & & & 1 & 11 & 37 & 1 & & & & & 50 & 54 \\
\hline 4 & & & & & 1 & 3 & 45 & 1 & & & & & & & 50 & 52 \\
\hline 5 & & & & & & 7 & 42 & 1 & & & & & & & 50 & 52 \\
\hline 6 & & & & & & 4 & 44 & 2 & & & & & & & 50 & 52 \\
\hline 7 & & & & 20 & & & & & & & & & & & 22 & 49 \\
\hline 8 & & & 1 & 5 & 44 & & & & & & & & & & 50 & 50 \\
\hline 9 & 1 & 6 & 42 & 1 & & & & & & & & & & & 50 & 48 \\
\hline 10 & & & & & & & & & 9 & 37 & 3 & 1 & & & 50 & 55 \\
\hline
\end{tabular}

For the sake of convenience for the comparison of karyotypes, the chromosomes were classified into the following 7 groups by considering the size and shape: acrocentrics (Ac), large metacentrics (Lm), medium-sized metacentrics ( $\mathrm{Mm})$, medium-sized submetacentrics (Msm), small metacentrics ( $\mathrm{Sm}$ ), and small submeta- or subtelocentrics (Ssm/st). According to the above-mentioned classification and designation, the chromosome constitutions of the ten specimens under study are represented as follows:

Specimen 1 ( ${ }^{7}$, Sapporo): $2 n=53$; they consist of 48 Ac, 1 $\mathrm{Mm}$ and $4 \mathrm{~m}$. One of the $4 \mathrm{~m}$ was outstanding by its extremely small size.

Specimen 2 (우, Naganuma) : $2 \mathrm{n}=59$ which contain $48 \mathrm{Ac}, 1$ $\mathrm{Mm}, 1 \mathrm{Msm}, 2 \mathrm{Sm}$ and $7 \mathrm{~m}$.

Specimen 3 ( ${ }^{\top}$, Naganuma) : $2 \mathrm{n}=54$; they are represented by $48 \mathrm{Ac}, 1 \mathrm{Lm}, 1 \mathrm{Sm}$ and $4 \mathrm{~m}$.

Specimen 4 (ठ, Naganuma) : $2 \mathrm{n}=52$ which consist of $48 \mathrm{Ac}$, $1 \mathrm{Msm}, 1 \mathrm{Sm}$ and $4 \mathrm{~m}$.

Specimen 5 (ठ, Naganuma) : $2 \mathrm{n}=52$ represented by 48 Ac, 1 $\mathrm{Lm}, 1 \mathrm{Ssm} / \mathrm{st}$ and $2 \mathrm{~m}$.

Specimen 6 (ð, Naganuma) : $2 \mathrm{n}=52$ showing $48 \mathrm{Ac}, 1 \mathrm{Mm}$ and $3 \mathrm{Sm}$.

Specimen 7 (우, Naganuma) : $2 \mathrm{n}=49$ consisting of $47 \mathrm{Ac}, 1 \mathrm{Ssm} /$ st and $1 \mathrm{~m}$.

Specimen 8 (ð, Shibecha) : $2 \mathrm{n}=50$ showing 48 Ac and $2 \mathrm{~m}$.

Specimen 9 (우, Oketo) : $2 \mathrm{n}=48$ consisting of $40 \mathrm{Ac}, 2 \mathrm{Mm}, 2$ Sm and 4 Ssm/st.

Specimen 10 (ð, Oketo) : $2 \mathrm{n}=55$; they comprise $49 \mathrm{Ac}, 2 \mathrm{Sm}$ and $4 \mathrm{~m}$. One of the $4 \mathrm{~m}$ appeared to be extremely small. 
Table II. Summary of karyotype analyses in ten specimens of Apodemus giliacus under study. For symbols see text

\begin{tabular}{c|c|cccccc|c|c}
\hline \multirow{2}{*}{$2 \mathrm{n}$} & \multirow{2}{*}{ Ac } & \multicolumn{5}{|c|}{ Biarmed chromosomes } & m & $\begin{array}{c}\text { Specimen } \\
\text { no. }\end{array}$ \\
\cline { 3 - 8 } & & Lm & Mm & Msm & Sm & Ssm/st & Total & & \\
\hline 59 & 48 & & 1 & 1 & 2 & & 4 & 7 & 2 \\
55 & 49 & & & & 2 & & 2 & 4 & 10 \\
54 & 48 & 1 & & & 1 & & 2 & 4 & 3 \\
53 & $\prime \prime$ & & 1 & & & & 1 & 4 & 1 \\
52 & $\prime \prime$ & 1 & & & & 1 & 2 & 2 & 5 \\
52 & $\prime \prime$ & & & 1 & 1 & & 2 & 2 & 4 \\
52 & $\prime \prime$ & & 1 & & 3 & & 4 & 0 & 6 \\
50 & $\prime \prime$ & & & & & & 0 & 2 & 8 \\
49 & 47 & & & & & 1 & 1 & 1 & 7 \\
48 & 40 & & 2 & & 2 & 4 & 8 & 0 & 9 \\
\hline
\end{tabular}

The chromosome numbers of these ten specimens are arranged in a declining order (see Table II). Worth-mentioning is the fact that all of the specimens studied show different karyotypes, and that the extreme karyotypic variability among different individuals can not be explicable by a simple mechanism. Generally speaking, the differences in number and constitution of biarmed elements and microchromosomes are considered to be the main factors which seem to cause the karyotypic variations of this species. On the other hand, it was shown that the number of acrocentrics seems to remain in a rather stable condition ranging from 47 to 49 , except specimen 9 which comprised only 40 such elements. In Figs. 1 and 2 are shown, as representatives, two karyotypes derived from specimens 2 and 9 which are remarkable by the highest and the lowest diploid numbers here obtained. However, there were some cases such as those between specimen 4 and 5, 6 and 9, and 7 and 8, in which their karyotypic relationships are accounted for by a rather simple mechanism such as the Robertsonian centric fusion or fission. Comparison of karyotypes shown in Figs. 2 and 3 may indicate the above relationships between specimens 9 and 6 beyond verbal description.

The chromosomes of five species of Apodemus were studied by Makino (1951) by means of the old testis-section method. The present study indicated that the chromosomes of the ten specimens of A. giliacus showed a remarkable polymorphism, and that none of the two different individuals here studied had the same chromosome constitution (Figs. 1 4). Furthermore, all of the ten different karyotypes here established were quite different from those reported in Apodemus speciosus and A. argenteus (Shimba et al., 1969), except the fact that the karyotype of specimen 9 is very akin to that of 
Apodemus speciosus given by Shimba et al. (1969). This specimen was carefully reexamined on the bases of the skeletal and several external characters by Kobayashi, but it was identified as A. giliacus. At the present moment, any conclusive statement on this respect should be postponed until more information becomes available.

\section{Herasabourpigananasen

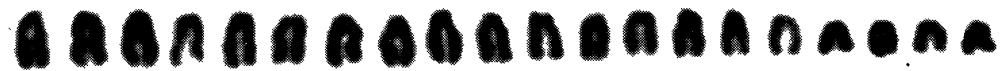 unananan ar a......

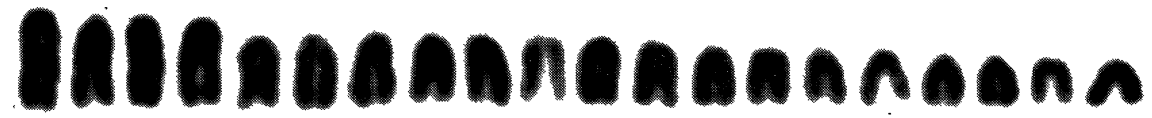

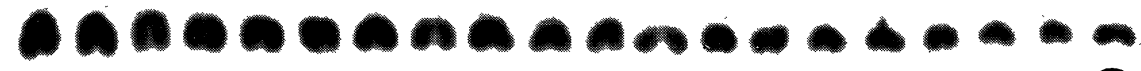 $\boldsymbol{\Delta x} \bullet \bullet \bullet \bullet \bullet$

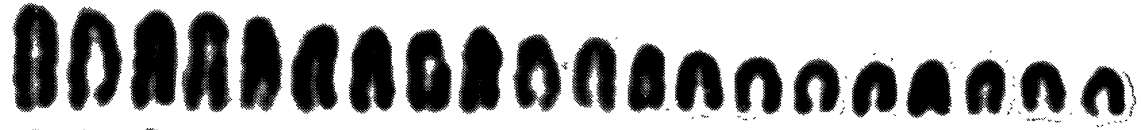

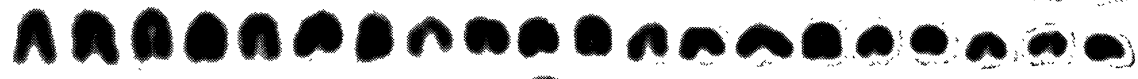

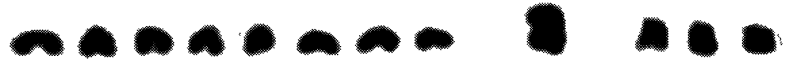

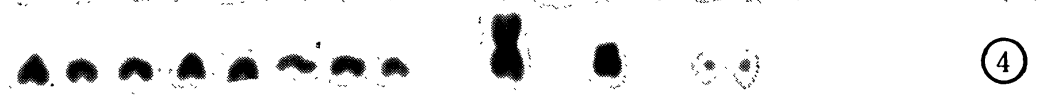

Figs. 1-4

Fig. 1. Karyotype from specimen 2, showing 2n, 59 (48 Ac, $1 \mathrm{Mm}, 1 \mathrm{Msm}$, $2 \mathrm{Sm}$ and $7 \mathrm{~m}$ ). Fig. 2. Karyotype from specimen 9, showing $2 \mathrm{n}, 48$ (40 Ac, $2 \mathrm{Mm}, 2 \mathrm{Sm}$ and $4 \mathrm{Ssm} / \mathrm{st}$ ). Fig. 3. Karyotype from specimen 6 , showing 2n, 52 (48 Ac, $1 \mathrm{Mm}$ and $3 \mathrm{Sm})$. Fig. 4. Karyotype from specimen 5, showing 2n, 52 (48 Ac, $1 \mathrm{Lm}, 1 \mathrm{Ssm} / \mathrm{st}$ and $2 \mathrm{~m}$ ).

Matthey (1970) reported many different karyotypes in pigmymice (Mus minutoides-musculoides), stating that the chromosomal mutations play there the part of a primary factor of isolation, previous to the gene mutations which later will allow the taxonomic determination of the species. The marked karyological variations of 
Apodemus giliacus may be related to the phylogenetic picture of this form which is rather primitive and divergent.

In the present study we failed to identify the sex chromosomes of this species, on account of the extreme diversity of the karyotype among different individuals of both sexes. Autoradiographic and meiotic studies are now in progress to deal with this and some other problems in relation to the homologue identification and supernumerary chromosomes. Further chromosomal investigations are also going on together with oecological, anatomical and enzymological studies.

Summary. Somatic chromosomes of Apodemus giliacus, a new form from Hokkaido, are investigated. The diploid numbers show a wide variation in different individuals. Chromosomal data are presented in some detail in Tables I and II. Many karyotypic variabilities observed are not explicable by a simple mechanism, though there are some which are in favor of the Robertsonian interpretation.

Acknowledgement. It is our pleasant duty to express cordial thanks to Professor Motomichi Sasaki for his helpful advice and expert criticism particularly for discussion.

\section{References}

Kobayashi, T. (1970): Revision of the genus Apodemus in Hokkaido. J. Fac. Agr. Hokkaido Univ., 56 (in press).

Makino, S. (1951): Studies on the murine chromosomes. V. A study of the chromosomes in Apodemus, especially with reference to the sex chromosome in meiosis. J. Morph., 88, 93-126.

Matthey, R. (1970): Nouvelles données sur la cytogénétique et la spéciation des Leggada (Mammalia-Rodentia-Muridae). Experientia, 26, 102-103.

Shimba, H., Itoh, M., Obara, Y., Kohno, S., and Kobayashi, T. (1969): A preliminary survey of the chromosomes in field mice, Apodemus and Clethrionomys. J. Fac. Sci. Hokkaido Univ. Ser. VI, Zool., 17, 257-262. 